\title{
Indications, results, and clinical impact of endoscopic ultrasound (EUS)-guided sampling in gastroenterology: European Society of Gastrointestinal Endoscopy (ESGE) Clinical Guideline

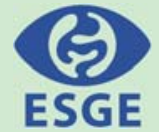

Authors

Institutions
J.-M. Dumonceau' ${ }^{1}$, M. Polkowski² , A. Larghì ${ }^{3}$, P. Vilmann ${ }^{4}$, M. Giovannini' ${ }^{5}$, J.-L. Frossard ${ }^{1}$, D. Heresbach ${ }^{6}$, B. Pujol ${ }^{7}$, G. Fernández-Esparrach ${ }^{8}$, E. Vazquez-Sequeiros ${ }^{9}$, A. Ginès ${ }^{8}$

Institutions are listed at the end of the article. submitted 31 March 2011 accepted after revision 9 June 2011

\section{Bibliography}

Dol http://dx.doi.org/ 10.1055/s-0030-1256754

Published online: 12.08 .2011

Endoscopy 2011; 43: 897-909

(c) Georg Thieme Verlag KG

Stuttgart · New York

ISSN 0013-726X

\section{Corresponding author}

J.-M. Dumonceau, MD, PhD

Division of Gastroenterology and Hepatology

Geneva University Hospitals Rue Gabrielle Perret-Gentil 4

1211 Genève 14

Switzerland

Fax: +41-22-3729366

jmdumonceau@hotmail.com
This article is part of a combined publication that expresses the current view of the European Society of Gastrointestinal Endoscopy (ESGE) about endoscopic ultrasound (EUS)-guided sampling in gastroenterology, including EUS-guided fine needle aspiration (EUS-FNA) and EUS-guided trucut biopsy (EUS-TCB), of submucosal tumors, diffuse esophageal/gastric wall thickening, pancreatic solid masses and cystic-appearing lesions, mediastinal lesions unrelated to lung or esophageal cancer, cancer of the esophagus, stomach, and rectum, lymph nodes of unknown origin, adrenal gland masses, and focal liver lesions. False-positive cytopathological results and needle tract seeding are also discussed. The present Clinical Guideline describes the results of EUS-guided

\section{Introduction}

$\nabla$

This Clinical Guideline describes the results obtained with endoscopic ultrasound (EUS)-guided sampling, describes the role of this technique in patient management, and makes recommendations on circumstances that warrant its use. For the general technique of EUS-guided sampling, particular techniques to obtain the highest yield possible depending on the lesion sampled, and sample processing, readers are referred to the associated Technical Guideline from the European Society of Gastrointestinal Endoscopy (ESGE) [1].

\section{Methods}

\section{$\nabla$}

The ESGE commissioned and funded this Guideline. The methodology was similar to that used for other ESGE Guidelines [2,3]. Briefly, subgroups were formed, each charged with a series of clearly defined key questions (see Appendix e1, available online). The committee chair worked with subgroup leaders to identify pertinent search terms that always included, as a minimum, "endoscopic sampling in the different clinical settings, considers the role of this technique in patient management, and makes recommendations on circumstances that warrant its use. A two-page executive summary of evidence statements and recommendations is provided. A separate Technical Guideline describes the general technique of EUS-guided sampling, particular techniques to maximize the diagnostic yield depending on the nature of the target lesion, and sample processing. The target readership for the Clinical Guideline mostly includes gastroenterologists, oncologists, internists, and surgeons while the Technical Guideline should be most useful to endoscopists who perform EUS-guided sampling.

ultrasonography" and words pertinent to specific key questions. Evidence tables were generated for each key question based on meta-analyses or randomized controlled trials (RCTs) if these were available; otherwise, case - control studies, retrospective analyses, and case series were included. The number of articles retrieved and selected for each task force is indicated in the Evidence table (see Appendix e2, available online). Evidence levels and recommendation grades used in this Guideline were slightly modified from those recommended by the amended Scottish Intercollegiate Guidelines Network ( Table 1) [4]. Subgroups agreed electronically on draft proposals that were presented to the entire group for general discussion during two meetings held in 2010 and 2011. The results of that discussion were incorporated into the subsequent Guideline version and again discussed using electronic mail until unanimous agreement was reached. Searches were re-run in February 2011 (this date should be taken into account for future updates). The final draft was approved by all members of the Guideline development group; it was sent to all individual ESGE members in March 2011 and, 
Table 1 Definitions of categories for evidence levels and recommendation grades used in this Guideline [4]

\begin{tabular}{|c|c|}
\hline \multicolumn{2}{|c|}{ Evidence level } \\
\hline $1++$ & $\begin{array}{l}\text { High quality meta-analyses, systematic reviews of RCTs, } \\
\text { or RCTs with a very low risk of bias }\end{array}$ \\
\hline $1+$ & $\begin{array}{l}\text { Well conducted meta-analyses, systematic reviews of RCTs, } \\
\text { or RCTs with a low risk of bias }\end{array}$ \\
\hline $1-$ & $\begin{array}{l}\text { Meta-analyses, systematic reviews, } \\
\text { or RCTs with a high risk of bias }\end{array}$ \\
\hline $2++$ & $\begin{array}{l}\text { High quality systematic reviews of case - control or cohort } \\
\text { studies; high quality case - control studies } \\
\text { or cohort studies with a very low risk of confounding, bias, or } \\
\text { chance and a high probability that the relationship is causal }\end{array}$ \\
\hline $2+$ & $\begin{array}{l}\text { Well conducted case - control or cohort studies with a low risk } \\
\text { of confounding, bias, or chance and a moderate probability that } \\
\text { the relationship is causal }\end{array}$ \\
\hline $2-$ & $\begin{array}{l}\text { Case - control or cohort studies with a high risk of confounding, } \\
\text { bias, or chance and a significant risk that the relationship is not } \\
\text { causal }\end{array}$ \\
\hline 3 & Nonanalytic studies, e.g. case reports, case series \\
\hline 4 & Expert opinion \\
\hline \multicolumn{2}{|c|}{ Recommendation grade } \\
\hline A & $\begin{array}{l}\text { At least one meta-analysis, systematic review, or RCT rated as } \\
1++ \text { and directly applicable to the target population } \\
\text { or a systematic review of RCTs } \\
\text { or a body of evidence consisting principally of studies rated as } \\
1+\text { directly applicable to the target population and demon- } \\
\text { strating overall consistency of results }\end{array}$ \\
\hline B & $\begin{array}{l}\text { A body of evidence including studies rated as } 2++ \text { directly ap- } \\
\text { plicable to the target population and demonstrating overall } \\
\text { consistency of results } \\
\text { or extrapolated evidence from studies rated as } 1++ \text { or } 1+\end{array}$ \\
\hline C & $\begin{array}{l}\text { A body of evidence including studies rated as } 1-\text { or } 2+\text { directly } \\
\text { applicable to the target population and demonstrating overall } \\
\text { consistency of results } \\
\text { or extrapolated evidence from studies rated as } 2++\end{array}$ \\
\hline D & $\begin{array}{l}\text { Evidence level } 2-, 3 \text { or } 4 \\
\text { or extrapolated evidence from studies rated as } 2+\end{array}$ \\
\hline
\end{tabular}

$\mathrm{RCT}$, randomized controlled trial.

after incorporation of their comments, it was endorsed by the ESGE Governing Board prior to submission to Endoscopy for international peer review. The final revised version was approved by all members of the Guideline development group before publication.

Evidence statements and recommendations are stated in italics, key evidence statements and recommendations are in bold. This Guideline will be considered for revision in 2014, or sooner if important new evidence becomes available. Any updates to the Guideline in the interim period will be noted on the ESGE website: http://www.esge.com/esge-guidelines.html.

\section{Summary of statements and recommendations}

\section{Submucosal tumors (SMTs)}

Data from selected centers suggest that endoscopic forceps biopsy with the so-called bite-on-bite technique can provide specimens adequate for diagnosis in a substantial proportion of cases (Evidence level 2-). The diagnostic yield of EUS-guided fine needle aspiration (EUS-FNA) cytology is moderate and limited by unsatisfactory immunostaining in a substantial proportion of patients (Evidence level $2+$ ); this may be improved by obtaining samples for cytopathological plus histopathological examinations (Evidence level
$2-)$. The diagnostic yield of EUS-guided trucut biopsy (EUS-TCB) is similar to that of EUS-FNA (Evidence level 2+). The potential impact of EUS-guided sampling on patient management varies according to many factors including clinical presentation, SMT characteristics (size, location, and echo features), and patient physical condition (Evidence level 4).

Bite-on-bite biopsy should be the first diagnostic step at centers where satisfactory results are achieved with this technique. When bite-on-bite biopsy fails or is not attempted, EUS-guided sampling with efforts at obtaining samples for histopathological evaluation should be performed (Recommendation grade C). For selected small lesions located in the second or third EUS layer, endoscopic resection may also be considered (Recommendation grade D). EUS-guided sampling is not likely to impact management and hence is generally not indicated in patients with the following (Recommendation grade $D$ ):

- Surgery planned because of SMT-related symptoms;

- SMT harboring typical echo features of a lipoma;

- Small $(<2 \mathrm{~cm})$ SMTs of the esophagus and stomach.

Also the clinical benefit of EUS-guided sampling in patients with hypoechoic esophageal or gastric SMTs $>2 \mathrm{~cm}$ is usually limited and should not be overstated (Recommendation grade $D$ ).

EUS-guided sampling is indicated in the following situations (Recommendation grade $D$ ):

- SMTs with a presumptive diagnosis of unresectable gastrointestinal stromal tumor (GIST) for which treatment with tyrosine kinase inhibitors is contemplated;

- patient previous history of malignancy with an SMT that may be consistent with a metastasis;

- suspected diagnosis of lymphoma, neuroendocrine tumor, or extrinsic tumor, based on EUS, biological, or clinical criteria.

For duodenal and colorectal SMTs, no recommendations are made due to insufficiency of data.

\section{Diffuse esophageal/gastric wall thickening}

Diagnostic accuracy of EUS-TCB for investigating diffuse esophageal/gastric wall thickening seems to be high (90\%), in particular when compared with that of EUS-FNA (60\%) (Evidence level $2+$ ). In patients with diffuse esophageal/gastric wall thickening, after failure of standard biopsy techniques to establish a diagnosis, we recommend performing EUS-TCB (Recommendation grade $C$ ). In the case of technical failure of EUS-TCB, EUSFNA could be indicated (Recommendation grade $D$ ).

\section{Pancreatic solid masses}

EUS-FNA presents a high diagnostic accuracy but a relatively low negative predictive value (NPV) for the diagnosis of pancreatic cancer. Due to this universal drawback of all sampling techniques available for the pancreas, preoperative sampling is generally not advised (i.e., for potentially resectable pancreatic tumors in operable patients). In other circumstances (e.g., neoadjuvant or palliative radio/chemotherapy), a pathological diagnosis is required; this can be obtained by sampling the primary pancreatic lesion or possible metastases (Evidence level 1+). Compared with ultrasoundguided or computed tomography (CT)-guided FNA of pancreatic masses, EUS-FNA seems to present a higher diagnostic accuracy, particularly for small lesions (Evidence level 2+). EUS-FNA can also demonstrate, in approximately $10 \%$ of patients, metastatic dissemination to distant lymph nodes, the peritoneum, or the liver that was unsuspected with other imaging techniques (Evidence level $2++$ ). Repeat EUS-FNA in patients with a high clinical suspicion for pancreatic cancer but indeterminate or negative findings 
at initial EUS-FNA allows improvement of diagnostic accuracy (Evidence level 2+).

In cases where sampling of a suspected pancreatic cancer is indicated, we recommend EUS-FNA as the first-line procedure. If lesions suspicious for metastases are discovered during EUS staging of a suspected pancreatic cancer in patients with an otherwise resectable mass, EUS-FNA of these lesions should be performed (Recommendation grade B). In patients with a high clinical suspicion for pancreatic cancer and indeterminate or negative findings at the initial sampling procedure, including EUS-FNA, EUS-FNA (possibly repeated) is recommended (Recommendation grade $\mathrm{C}$ ).

\section{Pancreatic cystic-appearing lesions}

Biochemical and cytopathological analyses of fluid aspirate obtained by EUS-FNA may help the differential diagnosis of pancreatic cystic-appearing lesions (Evidence level 1+). In some conditions, the cyst wall may be brushed during EUS; this technique may allow a higher diagnostic yield than FNA but it has been associated with frequent, sometimes severe, complications (including death) (Evidence level 2-).

If nonsurgical diagnosis of pancreatic cystic-appearing lesions may change patient management, EUS-FNA with determination of amylase and carcinoembryonic antigen (CEA) levels plus cytopathological examination of fluid aspirate is recommended for lesions $>2 \mathrm{~cm}$ in diameter (Recommendation grade B). EUSguided cyst wall brushing may be useful in well-selected cases (Recommendation grade $D$ ).

\section{Mediastinal lesions unrelated to lung or esophageal cancer}

Transesophageal EUS-FNA is safe and accurate for the diagnosis of solid lesions located in the posterior mediastinum. For mediastinal lymph nodes, the addition of FNA to EUS slightly increases sensitivity and significantly increases specificity for diagnosing the cause of lymph node enlargement (Evidence level 1-). EUS-FNA of noncystic mediastinal lesions of unknown origin impacts patient management in $>70 \%$ of cases (Evidence level $2+$ ). EUS-FNA of mediastinal cysts carries a risk of severe infection even if prophylactic antibiotics are administered (Evidence level 3).

We recommend transesophageal EUS-FNA for the initial work-up of solid mediastinal lesions and enlarged lymph nodes of unknown origin that are accessible to this technique (Recommendation grade $B$ ); we discourage EUS-FNA of mediastinal cysts (Recommendation grade $D)$.

\section{Esophageal cancer}

For initial lymph node staging in esophageal cancer, EUS-FNA is more accurate than EUS alone as well as than helical CT (Evidence level $2++)$; it also allows diagnosis of metastases undetected at CT in the left liver lobe in approximately $5 \%$ of patients. In patients who are considered for surgical resection, EUS-FNA may impact treatment decisions by correcting the stage determined by helical CT (usually towards a higher stage) in approximately one third of cases (Evidence level 2+). The impact of adding FNA to the staging based on EUS alone remains uncertain but there is limited evidence suggesting that EUS-FNA may change the management plan based on EUS alone (Evidence level 2-). EUS-FNA has higher accuracy than integrated fluorodeoxyglucose positron emission tomography and CT (integrated FDG-PET/CT) for lymph node staging. For lymph node re-staging and for predicting complete pathological response after neoadjuvant therapy, EUS-FNA has lower accuracy than integrated FDG-PET/CT (Evidence level 2+).

For initial staging, EUS-FNA should be performed whenever the cytological result is likely to affect the decision on what treatment option to choose in a given patient (e.g., primary surgical resection, or definitive or neoadjuvant chemoradiotherapy). Integrated FDG-PET/CT is recommended only in case of incomplete EUS examination (Recommendation grade D). For re-staging after neoadjuvant therapy, integrated FDG-PET/CT is recommended (Recommendation grade C). Whether EUS-FNA should be performed to obtain cytological confirmation of integrated FDG-PET/CT findings positive for lymph node metastasis requires further studies.

\section{Gastric cancer}

EUS-FNA modifies the management of patients with a gastric cancer by demonstrating distant metastases unsuspected with other imaging techniques in 8\%-15\% of cases (Evidence level 2+).

In patients with gastric cancer, we recommend performing EUSFNA of all suspected distant metastases detected during EUS examination only when it has the potential to change patient management (Recommendation grade $\mathrm{C}$ ).

\section{Rectal cancer}

For the initial staging of rectal cancer, EUS-FNA does not have more impact on patient management than EUS alone; in patients with perirectal lesions detected at EUS and a history of cancer, EUSFNA is useful to demonstrate or rule out cancer recurrence (Evidence level $2+$ ).

We recommend performing EUS-FNA of perirectal lesions only when it has the potential to change patient management, i.e. mostly in patients with a previous history of cancer, and not for rectal cancer staging (Recommendation grade $\mathrm{C}$ ).

\section{Lymph nodes of unknown origin}

EUS-FNA allows accurate determination of the nature of lymph nodes of unknown origin (Evidence level $2+$ ).We recommend performing EUS-FNA of lymph nodes of unknown origin if these are accessible, no other significant lymph node is easily accessible (e.g., subcutaneous lymph node), and a pathological result would likely affect patient management (Recommendation grade $C$ ).

\section{Adrenal gland masses}

EUS-FNA is an accurate and safe technique for sampling left adrenal gland masses (Evidence level 2+). In patients with lung cancer and an enlarged left adrenal gland, EUS-FNA of the left adrenal gland modifies disease stage and treatment strategy in approximately half of patients (Evidence level 2+); it is recommended if a cytopathological result positive for malignancy is likely to change patient management (Recommendation grade $\mathrm{C}$ ).

\section{Focal solid liver lesions}

Solid liver lesions may be safely sampled by EUS-FNA; the diagnostic yield and the impact on patient management are high (Evidence level $2+$ ). We recommend performing EUS-FNA of focal liver lesions accessible to EUS-FNA if: (i) a pathological result positive for malignancy would likely affect patient management, and (ii) the lesion is poorly accessible to percutaneous FNA or it is detected de novo by EUS or it has been sampled by percutaneous FNA with a nondiagnostic result (Recommendation grade $\mathrm{C}$ ). 
False-positive cytopathological results

The incidence of false-positive cytopathological results with EUSFNA samples ranges between 1.6\% and 5.3\% (Evidence level 2+). Flushing the working channel of the echoendoscope before every needle pass may reduce this risk (Evidence level 2-). The possibility of a false-positive diagnosis should be kept in mind when interpreting cytopathological results of EUS-FNA, particularly for EUS-FNA of lymph nodes in patients with luminal cancers (Recommendation grade C). We suggest flushing the working channel of the echoendoscope before every needle pass and collection of microcores to help prevent this outcome (Recommendation grade $D$ ).

\section{Needle tract seeding}

Needle tract seeding is extremely rare with EUS-FNA (Evidence level 3).

\section{Digestive wall lesions}

This section is devoted to circumscribed intramural solid lesions of the gastrointestinal (GI) tract, referred to as submucosal tumors (SMTs) and diffuse intramural infiltration of the GI tract presenting in the form of widespread, diffuse, GI wall thickening.

\subsection{Submucosal tumors (SMTs)}

Data from selected centers suggest that endoscopic forceps biopsy with the so-called bite-on-bite technique can provide specimens adequate for diagnosis in a substantial proportion of cases (Evidence level 2-). The diagnostic yield of EUS-guided fine needle aspiration (EUS-FNA) cytology is moderate and limited by unsatisfactory immunostaining in a substantial proportion of patients (Evidence level 2+); this may be improved by obtaining samples for cytopathological plus histopathological examinations (Evidence level $2-)$. The diagnostic yield of EUS-guided trucut biopsy (EUS-TCB) is similar to that of EUS-FNA (Evidence level $2+$ ). The potential impact of EUS-guided sampling on patient management varies according to many factors including clinical presentation, SMT characteristics (size, location, and echo features) and patient physical condition (Evidence level 4).

Bite-on-bite biopsy should be the first diagnostic step at centers where satisfactory results are achieved with this technique. When bite-on-bite biopsy fails or is not attempted, EUS-guided sampling with efforts at obtaining samples for histopathological evaluation should be performed (Recommendation grade $\mathrm{C}$ ). For selected small lesions located in the second or third EUS layer, endoscopic resection may also be considered (Recommendation grade D). EUS-guided sampling is not likely to impact management and hence is generally not indicated in patients with the following (Recommendation grade $D$ ):

- Surgery planned because of SMT-related symptoms;

- SMT harboring typical echo features of a lipoma;

- Small $(<2 \mathrm{~cm})$ SMTs of the esophagus and stomach.

Also the clinical benefit of EUS-guided sampling in patients with hypoechoic esophageal or gastric SMTs $>2 \mathrm{~cm}$ is usually limited and should not be overstated (Recommendation grade $D$ ).

EUS-guided sampling is indicated in the following situations (Recommendation grade $D$ ):

- SMTs with a presumptive diagnosis of unresectable gastrointestinal stromal tumor (GIST) for which treatment with tyrosine kinase inhibitors is contemplated;

- Patient previous history of malignancy with an SMT that may be consistent with a metastasis;
- Suspected diagnosis of lymphoma, neuroendocrine tumor, or extrinsic tumor based on EUS, biological, or clinical criteria.

For duodenal and colorectal SMTs, no recommendations are made due to insufficiency of data.

The term "SMT" encompasses a variety of conditions, including non-neoplastic lesions as well as benign, premalignant, and overtly malignant neoplasms that are located in the digestive wall beneath the epithelium. Overtly malignant SMTs are rare and vastly outnumbered by GISTs that are potentially malignant. The risk that an SMT is malignant or premalignant is associated with tumor size, echo features, and anatomic location (the risk is highest for gastric SMTs and very low for esophageal SMTs) [5,6]. The studies discussed below mostly included hypoechoic SMTs of the stomach (predominantly GISTs) and it is not certain that their results can be extrapolated to SMTs involving other parts of the GI tract.

Data on the diagnostic yield of bite-on-bite (or stacked, or tunneled) biopsy are inconsistent across the literature, with reported adequacy rates ranging from $17 \%$ to $94 \%$ [7-12]. Because of these discrepant results, local experience should be used to determine the role of this potentially valuable technique in the diagnostic algorithm. More advanced techniques (e.g., "unroofing" and "keyhole" techniques) seem promising but require further evaluation $[13,14]$. En bloc resection of lesions $<20 \mathrm{~mm}$ located in the second and third EUS layer is safe in experienced hands and it allows definitive pathological diagnosis [15].

EUS-FNA allows harvesting of representative material for cytopathological evaluation from most SMTs (70\%-84\%) (- Table 2) [8,16-21]. However, cytological material is often insufficient for performance of the immunostaining that is required to differentiate GIST and other mesenchymal tumors. There is limited evidence to suggest that this limitation may be partly overcome by processing EUS-FNA specimens for histopathological examination $[18,21,22]$. EUS-TCB is not superior to EUS-FNA; however, combining both techniques improves the diagnostic yield $[8,19,23]$. The mitotic index, and hence the malignant potential of GIST, cannot be reliably assessed on samples obtained by EUSguided techniques $[21,23,24]$. Data on the usefulness of the Ki-67 labeling index to circumvent this limitation are contradictory $[22,25,26]$. The above problems notwithstanding, it should be noted that when EUS-FNA or EUS-TCB provides an adequate sample, then the diagnosis is concordant with the final diagnosis in most cases. Only single cases of misdiagnoses have been reported $[8,16-19,21-23]$.

Algorithms for the management of patients with SMTs have been proposed but none of them has been prospectively validated $[19,27,28]$. Also, the impact of EUS-FNA on patient management has not been evaluated. The following recommendations are based exclusively on expert opinions and data extrapolated from available studies:

1. In patients with SMT-related symptoms (e.g., bleeding, digestive obstruction), EUS-guided sampling is not likely to impact management and hence is not indicated, except for the situations described in points 3 and $5 \mathrm{c}$ below.

2. EUS without FNA is sufficiently accurate to diagnose lipoma [29].

3. If an intramural metastasis, lymphoma, neuroendocrine tumor, or an extrinsic tumor is suspected, EUS-FNA or EUS-TCB should be considered because the management may substantially differ from the one recommended for other SMTs. Of note, primary carcinomas of the GI wall mimicking a SMT have been reported in many EUS series [5,16,19,22]. 
Table 2 Diagnostic yield of various endoscopic ultrasound (EUS)-guided sampling techniques in patients with submucosal tumors*.

\begin{tabular}{|c|c|c|c|c|c|c|}
\hline \multirow[t]{2}{*}{ First author, year } & \multirow{2}{*}{$\begin{array}{l}\text { Prospective/ } \\
\text { retrospective }\end{array}$} & \multirow[t]{2}{*}{ Patients, $\mathbf{n}$} & \multirow{2}{*}{$\begin{array}{l}\text { Sampling } \\
\text { technique }\end{array}$} & \multicolumn{3}{|l|}{ Specimens $\dagger$} \\
\hline & & & & Diagnostic & $\begin{array}{l}\text { Insufficient for } \\
\text { immunostaining }\end{array}$ & Nondiagnostic \\
\hline Philipper, 2010 [17] & Prospective & 47 & FNAC & $34 \%$ & $56 \%$ & $26 \%$ \\
\hline $\begin{array}{l}\text { Fernández-Esparrach, } \\
2010 \text { [19] }\end{array}$ & Prospective & 40 & FNAC & $53 \%$ & $18 \%$ & $30 \%$ \\
\hline Mekky, 2010 [16] & Retrospective & 141 & FNAC & $62 \%$ & $21 \%$ & $17 \%$ \\
\hline Hoda, 2009 [8] & Retrospective & 112 & FNAC & $62 \%$ & $22 \%$ & $16 \%$ \\
\hline Akahoshi, 2007 [18] & Prospective & 53 & FNAC+ FNAH & $79 \%$ & $0 \%$ & $21 \%$ \\
\hline Yoshida, 2009 [21] & n.r. & 49 & $F N A C+F N A H$ & $82 \%$ & $0 \%$ & $18 \%$ \\
\hline Turhan, 2010 [22] & Prospective & 50 & $\mathrm{FNAC}+\mathrm{FNAH}$ & $90 \%$ & $0 \%$ & $10 \%$ \\
\hline Hoda, 2009 [8] & Retrospective & 15 & $\mathrm{TCB}$ & $47 \%$ & $13 \%$ & $40 \%$ \\
\hline $\begin{array}{l}\text { Fernández-Esparrach, } \\
2010 \text { [19] }\end{array}$ & Prospective & 40 & $\mathrm{TCB}$ & $55 \%$ & $5 \%$ & $40 \%$ \\
\hline Polkowski, 2009 [23] & Prospective & 49 & TCB & $63 \%$ & $14 \%$ & $22 \%$ \\
\hline $\begin{array}{l}\text { Fernández-Esparrach, } \\
2010 \text { [19] }\end{array}$ & Prospective & 40 & $\mathrm{TCB}+\mathrm{FNAC}$ & $78 \%$ & n.r. & n.r. \\
\hline
\end{tabular}

FNAC, fine needle aspiration cytology; FNAH, fine needle aspiration histology; n.r., not reported; TCB, trucut biopsy.

* Selected studies that included more than 25 patients, were published after 2000 , and provided sufficient data. Most (84\%) submucosal tumors evaluated in these studies

involved the stomach. The proportions of esophageal, duodenal and rectal tumors were $12 \%, 3 \%$, and $1 \%$, respectively.

$\dagger$ Specimens were categorized as diagnostic (adequate for diagnosis, including immunostaining when indicated), adequate for cytological or histological evaluation but insufficient for immunostaining, and nondiagnostic. Percentages may not add to $100 \%$ because of rounding.

4. Esophageal SMTs are rarely malignant (1\% of cases) and a pathological diagnosis is unlikely to change patient management, in particular when the tumor is $<2 \mathrm{~cm}[5,6]$. Sampling of esophageal SMTs should be considered in patients with large and/or otherwise suspicious SMTs but no more specific recommendations can be provided.

5. Gastric SMTs:

a) The management of incidental gastric SMTs $<2 \mathrm{~cm}$ is unlikely to be affected by EUS-FNA or EUS-TCB because such lesions harbor a very low risk of progression to clinically evident tumors and are likely more prevalent than previously thought [30-32]. Surveillance is a valid option in such cases $[33,34]$.

b) Three quarters of gastric hypoechoic SMTs $>2 \mathrm{~cm}$ are GISTs $[17,19,23]$. Most of these tumors have a very low malignant potential; however, some pose a greater risk because of high mitotic activity [17,22,23,34]. The usefulness of EUS-FNA or EUS-TCB in this setting seems limited due to the factors discussed above (limited diagnostic yield and no capability to determine the mitotic index). As laparoscopic wedge resection of the SMT represents a safe option for most patients [35], it is felt that EUS-guided sampling can be omitted in most cases and reserved only for patients who are poor surgical candidates or those with the tumor located in areas difficult to resect such as the cardia.

c) EUS-FNA or EUS-TCB is likely to impact the management in patients with a presumptive diagnosis of unresectable GIST in whom primary treatment with tyrosine kinase inhibitors is considered and confirmation of the diagnosis and CD117 status are required [33,34].

6. For duodenal and colorectal SMTs, data are insufficient to permit recommendations but it should be kept in mind that an SMT in patients with a history of rectal cancer may indicate local recurrence [36].

\subsection{Diffuse esophageal/gastric wall thickening}

Diagnostic accuracy of EUS-TCB for investigating diffuse esophageal/gastric wall thickening seems to be high (90\%), in particular when compared with that of EUS-FNA (60\%) (Evidence level 2+). In patients with diffuse esophageal/gastric wall thickening, after failure of standard biopsy techniques to establish a diagnosis, we recommend performing EUS-TCB (Recommendation grade C). In the case of technical failure of EUS-TCB, EUS-FNA could be indicated (Recommendation grade D).

Diffuse GI wall thickening is predominantly observed in the stomach and, less frequently, in the esophagus and rectum. Malignant causes include linitis plastica and, less frequently, lymphoma or diffuse metastasis. Benign causes are multiple, including eosinophilic infiltration, Zollinger-Ellison syndrome, Ménétrier's disease, and amyloidosis [37]. In subepithelial infiltrating tumors, standard endoscopic biopsy sampling often yields falsenegative results and the diagnostic yield of bite-on-bite biopsy sampling is unknown, although this technique is commonly used [38].

At least in the stomach, EUS without sampling is relatively accurate in discriminating malignant from benign conditions: in a prospective study of 61 patients, the thickening of the submucosa and/or muscularis propria (as opposed to thickening limited to the mucosa) was the single independent predictor of malignancy; the clinical impact of this feature was high because the probability of malignancy was $95 \%$ vs. $5 \%$, respectively, depending on whether deep wall layers were thickened or not [39].

Data on the diagnostic yield of EUS-FNA and EUS-TCB in patients with diffuse GI wall thickening are scarce. In a prospective study [40], the diagnostic accuracy of EUS-FNA was significantly lower for diffuse GI wall thickening as compared with all other indications and, in another large prospective study [41], the sensitivity for cancer diagnosis was only $62 \%$. No data about the impact of EUS-FNA for diffuse GI wall thickening have been reported. EUSTCB holds promise as it yielded high sensitivity and accuracy for the diagnosis of cancer ( $84 \%$ and $90 \%$, respectively) in a prospective series of 31 patients with a thickened esophageal/gastric wall 
[42]. EUS-TCB significantly impacted patient management in $42 \%$ of these patients, in particular by avoiding surgery in $35 \%$ of them. These results need to be confirmed in larger studies before firm recommendations can be made.

\section{Pancreatic solid masses \\ $\nabla$}

EUS-FNA presents a high diagnostic accuracy but a relatively low negative predictive value (NPV) for the diagnosis of pancreatic cancer. Due to this universal drawback of all sampling techniques available for the pancreas, preoperative sampling is not generally advised (i.e., for potentially resectable pancreatic tumors in operable patients). In other circumstances (e.g., neoadjuvant or palliative radio/chemotherapy), a pathological diagnosis is required; this can be obtained by sampling the primary pancreatic lesion or possible metastases (Evidence level 1+). Compared with ultrasoundguided or computed tomography (CT)-guided FNA of pancreatic masses, EUS-FNA seems to present a higher diagnostic accuracy, particularly for small lesions (Evidence level 2+). EUS-FNA can also demonstrate, in approximately $10 \%$ of patients, metastatic dissemination to distant lymph nodes, the peritoneum, or the liver that was unsuspected with other imaging techniques (Evidence level $2++$ ). Repeat EUS-FNA in patients with a high clinical suspicion for pancreatic cancer but indeterminate or negative findings at initial EUS-FNA allows improvement of diagnostic accuracy (Evidence level $2+$ ).

In cases where sampling of a suspected pancreatic cancer is indicated, we recommend EUS-FNA as the first-line procedure. If lesions suspicious for metastases are discovered during EUS staging of a suspected pancreatic cancer in patients with an otherwise resectable mass, EUS-FNA of these lesions should be performed (Recommendation grade B). In patients with a high clinical suspicion for pancreatic cancer and indeterminate or negative findings at the initial sampling procedure, including EUS-FNA, EUS-FNA (possibly repeated) is recommended (Recommendation grade $C$ ).

The differential diagnosis of solid pancreatic masses includes ductal adenocarcinoma ( $>85 \%$ of cases), neuroendocrine tumors, metastases, acinar cell carcinomas, lymphomas, inflammatory pseudotumors, and very rare diseases such as pancreatoblastomas and solid pseudopapillary tumors. Pancreatic solid masses suspicious for cancer may be classified into two categories: (i) masses that will not be resected because they are locally advanced, associated with metastases, or they present in patients with a poor physical condition; and (ii) potentially resectable masses. For the first category, sampling in order to obtain a definitive diagnosis is usually desirable to assist with counseling and planning palliation while, for the second category, it is generally not recommended because the results of EUS-FNA (or any other nonsurgical sampling technique) are unlikely to affect further management due to the relatively low NPV of EUS-FNA for cancer diagnosis [43]. Arguments for EUS-FNA in potentially resectable tumors include an established protocol of preoperative neoadjuvant therapy, a patient demand for a conclusive diagnosis of cancer before surgery and, lastly, exclusion of unusual tumors (e.g., lymphoma, some pancreatic metastases) that would not benefit from surgery [44].

A large review (28studies involving 4225 patients in total) of the performance of EUS-FNA in differentiating benign vs. malignant pancreatic masses found median figures for sensitivity, specificity, NPV, and diagnostic accuracy of $83 \%$ (range, 54\%-95\%), $100 \%$ (range, $71 \%-100 \%$ ), $72 \%$ (range, $16 \%-92 \%$ ) and $88 \%$ (range, 65\%-96\%), respectively [43]. The wide ranges reported above may be related to the use of varying definitions to classify cytopathological results as benign or malignant as well as to the exclusion of nondiagnostic specimens in some studies. New techniques including contrast-enhanced EUS and elastosonoendoscopy [45-47], DNA analysis [48], and K-ras mutation determination on FNA aspirates [49-51], are being developed to increase the NPV of EUS-FNA ( $72 \%$ in this review). In patients with indeterminate or negative findings at initial EUS-FNA and a high clinical suspicion for pancreatic cancer, repetition of EUS-FNA is strongly advised: a retrospective review of 24 consecutive patients showed that repeating EUS-FNA facilitated determination of the true status of disease in 20 patients (84\%) with inconclusive findings at initial EUS-FNA [52]; another prospective study showed that EUS-FNA repeated up to three times increased sensitivity for cancer diagnosis from $68 \%$ to $92 \%$ [53]. Both studies used rapid on-site evaluation for the initial and subsequent EUSFNA.

For the diagnosis of pancreatic neuroendocrine tumors, high sensitivity and diagnostic accuracy have been reported in two large retrospective studies that used immunocytochemistry for analyzing EUS-FNA samples [54,55]. EUS-FNA helped in assessment of the malignant behavior of pancreatic neuroendocrine tumors and was able to predict 5-year survival [56,57]. Determination of Ki-67 expression in EUS-FNA samples seems to be well correlated with that measured in surgical specimens and with the patient prognosis $[58,59]$. Metastatic lesions may also be demonstrated by EUS-FNA: in a series of 114 consecutive patients with focal pancreatic lesions identified on CT, EUS-FNA allowed demonstration of metastases of an extrapancreatic cancer in $11 \%$ of cases [60]. Finally, in cases suspicious for autoimmune pancreatitis or pancreatic lymphoma where pancreas sampling is indicated, specific techniques (namely, EUS-TCB and flow cytometry) may be useful [27,61].

Data comparing EUS-FNA vs. percutaneous CT- or ultrasoundguided FNA of pancreatic masses are limited [62-65]. In the single RCT available to date, 84 patients underwent CT- or ultrasound-guided FNA $(n=43)$ vs. EUS-FNA $(n=41)$ of a solid pancreatic mass [63]. EUS-FNA had numerically higher sensitivity and diagnostic accuracy than CT/ultrasound-FNA (84\% vs. $62 \%$ and $89 \%$ vs. $72 \%$, respectively) but the difference was not statistically significant. Three other series retrospectively evaluated 70,149 and 1050 FNA procedures [62,64,65]. Only the largest study showed a significant difference, with a higher accuracy of EUS-FNA compared with CT/ultrasound-guided FNA for masses $<3 \mathrm{~cm}$ [65]. In addition, a cost-minimization study has demonstrated that EUS-FNA is the best initial test and the preferred secondary method after a failed alternative sampling procedure for the diagnosis of suspected pancreatic cancer [66].

An important advantage of EUS-FNA over the percutaneous route is the presumed lower risk of peritoneal seeding [67] and the ability to provide supplemental staging information by sampling of: (i) lymph node metastases in the celiac, lumboaortic, retroduodenopancreatic, and superior mesenteric regions, (ii) small hepatic lesions missed at other imaging modalities [68], and (iii) small pockets of previously undetected ascites [69]; all these sites when positive for malignancy indicate a poor prognosis, with an impact on patient management [70]. In a prospective study, $12 \%$ of 99 operable patients were found by EUS-FNA to have metastasis in lymph nodes $(n=6)$, liver $(n=4)$, ascites $(n=1)$, and retroperitoneum $(n=1)$ that were unsuspected at ultrasound/CT [71]. The percutaneous technique may still be indicated in patients who 
are at risk for sedation-related complications and in those with surgically altered upper GI anatomy [72].

\section{Pancreatic cystic-appearing lesions}

$\nabla$

Biochemical and cytopathological analyses of fluid aspirate obtained by EUS-FNA may help the differential diagnosis of pancreatic cystic-appearing lesions (Evidence level 1+). In some conditions, the cyst wall may be brushed during EUS; this technique may allow a higher diagnostic yield than FNA but it has been associated with frequent, sometimes severe, complications (including death) (Evidence level 2-).

If nonsurgical diagnosis of pancreatic cystic-appearing lesions may change patient management, EUS-FNA with determination of amylase and carcinoembryonic antigen (CEA) levels plus cytopathological examination of fluid aspirate is recommended for lesions $>2 \mathrm{~cm}$ in diameter (Recommendation grade B). EUS-guided cyst wall brushing may be useful in well-selected cases (Recommendation grade $D)$.

Pancreatic fluid collections mostly consist of benign cystic neoplasms with or without a malignant potential (namely, intraductal papillary mucinous neoplasm [IPMN] and mucinous cystadenoma [MCA], or serous cystadenomas, respectively), inflammatory pseudocysts, and malignant cysts such as mucinous cystadenocarcinomas (MCAC). In a large multicenter study, the accuracy of EUS morphology for differentiating between MCA/MCAC and nonmucinous lesions was low (51\%) [73]. The analysis of CEA in fluid aspirate yielded a higher accuracy in a pooled analysis ( Table 3) [74]. The measurement of amylase level is also useful because a value $<250 \mathrm{U} / \mathrm{L}$ virtually excludes pancreatic pseudocyst. Nevertheless, the value of all of these analyses is limited by: (i) a relatively low sensitivity for distinguishing MCA/MCAC from serous cystadenomas and pseudocysts, and (ii) the requirement for a minimum of $1 \mathrm{~mL}$ of liquid to perform the analysis, a demand that is not feasible with lesions $<1 \mathrm{~cm}$ in diameter. The usefulness of other analyses, including total DNA, K-ras mutation, and proteomic analysis on fluid aspirate is currently being investigated [75 - 77].

The analysis of biochemical markers is complemented by cytopathological examination of the aspirate. Cytopathological examination yields a sensitivity of approximately $50 \%$ for the diagnosis of malignancy [74]. EUS-guided fluid aspiration may be complemented by cyst wall brushing if a 19-G needle is used (the lesion has to be $>2 \mathrm{~cm}$ in diameter and those located in the head of the pancreas or the uncinate process are difficult to reach due to the rigidity of the needle). In the two controlled studies of EUS-guided cyst wall brushing reported to date in full-text papers [78,79], brushing had a higher sensitivity than FNA for the cytopathological diagnosis of intracellular mucin in identical patients (62\% vs. $23 \%$, respectively; $P=0.001)$ and it was superior for detecting diagnostic cells ( $73 \%$ vs. $36 \%$, respectively; $P=0.08$ ) and mucinous cells ( $50 \%$ vs. $18 \%$, respectively; $P=0.016$ ). However, a final diag- nosis was not available for all patients in these studies, and this technique is not widely used, possibly due to potential complications: in three prospective studies involving a total of 73 patients, morbidity associated with cyst wall brushing was $9.5 \%$ and two patients required hospitalization due to post-procedure pancreatitis $[78,80,81]$. One procedure-related death has also been reported [79]. Some authors recommend cyst wall brushing in selected patients, namely in those with prior inconclusive FNA who have cysts suspicious for malignant transformation or in those who are poor surgical candidates and are considered for cyst ablation techniques [78].

\section{Mediastinal lesions unrelated to lung or esophageal cancer \\ $\nabla$}

Transesophageal EUS-FNA is safe and accurate for the diagnosis of solid lesions located in the posterior mediastinum. For mediastinal lymph nodes, the addition of FNA to EUS slightly increases sensitivity and significantly increases specificity for diagnosing the cause of lymph node enlargement (Evidence level 1-). EUS-FNA of noncystic mediastinal lesions of unknown origin impacts patient management in $>70 \%$ of cases (Evidence level $2+$ ). EUS-FNA of mediastinal cysts carries a risk of severe infection even if prophylactic antibiotics are administered (Evidence level 3).

We recommend transesophageal EUS-FNA for the initial work-up of solid mediastinal lesions and enlarged lymph nodes of unknown origin that are accessible to this technique (Recommendation grade $B$ ); we discourage EUS-FNA of mediastinal cysts (Recommendation grade $D$ ).

The posterior mediastinum is accessible by transesophageal EUSFNA; in this location, lesions most frequently consist of enlarged lymph nodes. Endosonographic criteria have been proposed to establish the benign or malignant nature of lymph nodes [82]. In a meta-analysis of 76 noncomparative, retrospective or prospective cohort series that used either EUS-FNA or EUS to investigate mediastinal lymph nodes, it was found that compared with EUS, EUS-FNA had a slightly higher sensitivity ( $88 \%$ vs. $85 \%$ ) and a significantly higher specificity (96\% vs. $85 \%$ ) for diagnosing the cause of lymph node enlargement [83]. Compared with alternative techniques available for sampling the mediastinum, EUSFNA is safer and less invasive: CT-guided biopsy has been associated with pneumothorax in a high percentage of cases and mediastinoscopy is a surgical, thus more invasive, procedure [84]. We recommend mediastinoscopy or CT-guided biopsy as second-line approaches.

The ability of EUS-FNA to diagnose lymph node metastases deriving from cancers located outside of the mediastinum and the lungs has been demonstrated in two case series involving patients with breast cancer or pancreatic/periampullary cancers $[85,86]$. Lymphoma has been diagnosed with a high accuracy (96\%) in a prospective series of 104 patients with lymph nodes of unknown origin (50 patients had lymph nodes located in the

\begin{tabular}{|c|c|c|c|c|c|}
\hline Cutoff & Diagnosis & Sensitivity, \% & Specificity, \% & Accuracy, \% & Table 3 Biochemical analyses for \\
\hline Amylase $<250 \mathrm{U} / \mathrm{L}$ & SCA, MCA, MCAC & 44 & 98 & 65 & the diagnosis of cystic-appearing \\
\hline$C E A<5 \mathrm{ng} / \mathrm{mL}$ & SCA, pseudocyst & 50 & 95 & 67 & \\
\hline CEA $>800 \mathrm{ng} / \mathrm{mL}$ & MCA, MCAC & 48 & 98 & 79 & \\
\hline
\end{tabular}

CEA, carcinoembryonic antigen; SCA, serous cystadenoma; MCA, mucinous cystadenoma; MCAC, mucinous cystadenocarcinoma. Adapted with permission from van der Waaij et al. Cyst fluid analysis in the differential diagnosis of pancreatic cystic lesions: a pooled analysis. Gastrointest Endosc 2005; 62: 383-389. 
mediastinum and 48 had a lymphoma) [87]. The diagnosis of lymphoma is frequently missed at cytopathological examination of EUS-FNA samples; this can be remedied by subjecting EUSFNA specimens to flow cytometry or by on-site isolation of whitish fragments for histopathological examination [88]. EUS-FNA is also very useful for the diagnosis of infectious and inflammatory diseases affecting the mediastinum, including extrapulmonary tuberculosis and sarcoidosis $[89,90]$. It has been suggested that using a 19-G needle to obtain a core biopsy was useful in the latter condition [91]. In a prospective series of 60 patients suspected of having tuberculosis in an area endemic for the disease [92], EUS-FNA of isolated mediastinal lymph nodes had a diagnostic yield of $93 \%$.

Concerning mediastinal cysts, EUS-FNA has been associated with severe infectious complications despite the administration of prophylactic antibiotics [93-97], and it is unlikely to impact patient management. Therefore, the indication of EUS-FNA in mediastinal cysts requires a careful consideration of the balance between benefits and risks in each patient.

The impact of EUS-FNA on the management of patients with posterior mediastinal lesions was analyzed in five studies that involved 444 patients in total (one prospective [98], four retrospective [99-102]). Globally, the proportion of mediastinal lesions with a final diagnosis of malignancy and the impact on patient management were in the range of $56 \%-64 \%$ and $70 \%-87 \%$ of cases, respectively. Definitions of impact on management varied between studies but most frequently consisted of avoidance of surgery. Hirdes et al. emphasized the risk of a negative impact on patient management related to inadequate or false-negative EUS-FNA samples (this affected $7 \%$ of their patients) [100]. In that study, a mean cost reduction of $472 €$ per patient was observed by using EUS-FNA compared with alternative diagnostic procedures, and complications (nonfatal perforations) were reported in $0.9 \%$ of patients. Three of the five studies cited above specifically reported on the impact of EUS-FNA in patients investigated for mediastinal lesions of unknown origin ( $\mathrm{n}=109)$, as opposed to the staging of a known malignancy [98,99,101]. The final diagnosis for the mediastinal lesions was a malignancy in $30 \%-$ $72 \%$ of patients and EUS-FNA had an impact on patient management in $73 \%-94 \%$ of them, most frequently by guiding therapy and avoiding surgery.

\section{Esophageal cancer \\ $\nabla$}

For initial lymph node staging in esophageal cancer, EUS-FNA is more accurate than EUS alone as well as than helical CT (Evidence level $2++$ ); it also allows diagnosis of metastases undetected at CT in the left liver lobe in approximately $5 \%$ of patients. In patients who are considered for surgical resection, EUS-FNA may impact treatment decisions by correcting the stage determined by helical CT (usually towards a higher stage) in approximately one third of cases (Evidence level 2+). The impact of adding FNA to the staging based on EUS alone remains uncertain but there is limited evidence suggesting that EUS-FNA may change the management plan based on EUS alone (Evidence level 2-). EUS-FNA has higher accuracy than integrated fluorodeoxyglucose positron emission tomography and CT (integrated FDG-PET/CT) for lymph node staging. For lymph node re-staging and for predicting complete pathological response after neoadjuvant therapy, EUS-FNA has lower accuracy than integrated FDG-PET/CT (Evidence level 2+).

For initial staging, EUS-FNA should be performed whenever the cytological result is likely to affect the decision on what treatment option to choose in a given patient (e.g., primary surgical resection, or definitive or neoadjuvant chemoradiotherapy). Integrated FDGPET/CT is recommended only in case of incomplete EUS examination (Recommendation grade $D$ ). For re-staging after neoadjuvant therapy, integrated FDG-PET/CT is recommended (Recommendation grade C). Whether EUS-FNA should be performed to obtain cytological confirmation of integrated FDG-PET/CT findings positive for lymph node metastasis requires further studies.

Despite continuous technological progress in the field of CT Scan and FDG-PET scanning, EUS is still recognized as the most accurate imaging method for initial locoregional staging in esophageal cancer [103]. Consequently, it is recommended that patients who have no distant metastases on CT (and/or FDG-PET) should undergo EUS [104,105]. Whether adding EUS-FNA to this standard staging algorithm significantly changes treatment decisions has not been well studied. Although many studies reported excellent sensitivity ( $88 \%-100 \%)$, specificity (100\%), and accuracy $(87 \%-100 \%)$ of EUS-FNA for detection of lymph node metastases [106-109], these studies were retrospective, focused mostly on celiac lymph nodes, had high potential for selection bias, and relied on an imperfect gold standard [103]. The only study that overcame these limitations was a prospective blinded comparison conducted in 76 consecutive patients in whom pathological evaluation of resected lymph nodes was available ( Table4) [110]. The accuracy of EUS-FNA for lymph node staging (87\%) was higher than that of EUS alone (74\%; $P=$ $0.01)$ or that of helical CT $(51 \% ; P<0.001)$.

EUS-FNA may affect patient management mostly by providing cytopathological confirmation of metastasis to regional lymph nodes, to nonregional lymph nodes (mostly celiac) or to distant sites. The true impact of EUS-FNA on patient management is difficult to measure because treatment decisions are guided not only by the presence of lymph node or distant metastases but also by many other factors including patient performance status and tumor location, histology, and infiltration depth (T-stage). In addition, management algorithms vary between institutions $[110,111]$. Finally, it is often difficult to separate the impact of EUS-FNA from that of EUS alone, and the difference in lymph node staging accuracy between EUS alone and EUS-FNA, albeit statistically significant, is relatively small [110]. Despite these reservations, there is evidence to suggest that EUS-FNA changes the management plan based on EUS alone:

\begin{tabular}{|llll|}
\hline Test & Sensitivity (95\%Cl) & Specificity (95\%Cl) & Accuracy (95\%Cl) \\
\hline EUS & $71 \%(56 \%-83 \%)$ & $79 \%(59 \%-92 \%)$ & $74 \%(62 \%-83 \%)$ \\
\hline EUS-FNA & $83 \%(70 \%-93 \%)$ & $93 \%(77 \%-99 \%)$ & $87 \%(77 \%-94 \%)$ \\
\hline Helical CT & $29 \%(17 \%-44 \%)$ & $89 \%(72 \%-98 \%)$ & $51 \%(40 \%-63 \%)$ \\
\hline
\end{tabular}

$\mathrm{Cl}$, confidence interval; EUS, endoscopic ultrasound; FNA, fine needle aspiration; CT, computed tomography

* Data from a prospective blinded study in 76 consecutive patients with pathological verification [110].
Table 4 Performance characteristics of various techniques in the detection of lymph node metastases from esophageal carcinoma*. Both EUS-FNA and EUS alone were more sensitive and more accurate than was helical CT. 
- The prospective study by Vazquez-Sequeiros et al. discussed above found that EUS-FNA (but not EUS alone) was able to significantly modify tumor stage determined by helical CT (usually towards a higher stage) in $38 \%$ of patients but the study did not directly assess the impact of EUS-FNA on patient management [110].

- In two series (one prospective and one retrospective) that involved a total of 307 patients, demonstration by EUS-FNA of lymph node metastases distant from the primary cancer changed the management plan in $7 \%-12 \%$ of patients [71,107].

- Metastases to the left liver lobe (median size, $5 \mathrm{~mm}$ ) or collections of malignant pleural fluid unsuspected at CT were diagnosed by EUS-FNA in 3\%-5\% of patients in a prospective and a retrospective study that together included a total of 207 patients $[71,112]$.

- EUS-FNA has also been used in a prospective study to select the surgical approach in patients with a resectable distal esophageal carcinoma and mediastinal lymph nodes visualized on EUS: EUS-FNA changed the management in $23 \%$ of 48 patients, by allocating patients with positive lymph nodes to transthoracic esophagectomy, and those without demonstrated malignant lymph node involvement to transhiatal resection that offers limited capability of lymph node removal [113].

Integrated FDG-PET/CT has been compared with EUS-FNA for initial lymph node staging in a retrospective study that involved 57 patients with lymph node metastasis confirmed at pathological examination [114]. EUS was significantly more sensitive than FDG-PET/CT for diagnosing lymph node metastasis (86\% vs. $44 \%$, $P<0.0001$ ). Of note, FNA had been performed to confirm lymph node metastasis suspected on the basis of EUS criteria in approximately one third of cases only. These data confirm those of a prospective study that showed that the addition of FDG-PET to EUS and CT did not change patient management if a complete EUS examination had been performed [115].

After chemoradiotherapy, the accuracy of lymph node staging by EUS-FNA (78\%) was found in a prospective study of 48 patients to be similar to that of CT (78\%) and significantly lower than that of integrated FDG-PET/CT (93\%; $P=0.04)$ [116]. The latter method was also superior in predicting complete pathologic response.

\section{Gastric cancer}

$\nabla$

EUS-FNA modifies the management of patients with a gastric cancer by demonstrating distant metastases unsuspected with other imaging techniques in 8\%-15\% of cases (Evidence level $2+$ ).

In patients with gastric cancer, we recommend performing EUSFNA of all suspected distant metastases detected during EUS examination only when it has the potential to change patient management (Recommendation grade $C$ ).

In patients with gastric cancer, malignant involvement of distant intra-abdominal lymph nodes (e.g., retropancreatic, mesenteric, and para-aortic lymph nodes) or of mediastinal lymph nodes distant from the primary tumor is indicative of a metastatic disease that qualifies the patient for palliation rather than resection with curative intent. In a prospective series of 62 patients with gastric cancer who were fit for surgery, EUS-FNA was performed for staging purposes in 12 patients (19\%); it demonstrated the presence of metastases in 8 patients (13\%) [71]. After exclusion of three patients with metastases suspected by CT and/or percuta- neous ultrasound, the actual clinical impact of EUS-FNA was $8 \%$. A more recent, retrospective, study involved 234 consecutive patients referred for management of a gastric cancer; 81 (35\%) had EUS-FNA targeting 99lesions that were suspicious for distant metastases according to echo features and locations [104]. Most (79\%) lesions sampled consisted of mediastinal lymph nodes. Overall, 38 patients had distant metastases demonstrated by EUS-FNA (23 [61\%] had the primary tumor in the cardia). After exclusion of four patients with liver metastases suspected at CT, EUS-FNA was judged by a board of surgeons to change patient management in 34 patients (15\%) by avoiding unnecessary surgery.

\section{Rectal cancer \\ $\nabla$}

For the initial staging of rectal cancer, EUS-FNA does not have more impact on patient management than EUS alone; in patients with perirectal lesions detected at EUS and a history of cancer, EUSFNA is useful to demonstrate or rule out cancer recurrence (Evidence level $2+$ ).

We recommend performing EUS-FNA of perirectal lesions only when this has the potential to change patient management, i.e. mostly in patients with a previous history of cancer, and not for rectal cancer staging (Recommendation grade $C$ ).

In the preoperative staging of rectal cancer, a single study has assessed the potential impact of EUS-FNA [117]. It showed that EUS-FNA added almost no relevant information to EUS alone: therapy decisions made by a colorectal surgeon after sequential disclosure of, first, the results of EUS alone and, secondly, the results of EUS-FNA, were identical in 79 of 80 patients who were evaluated prospectively. In that study, all non-juxtatumoral lymph nodes that were detected at EUS were sampled; 41 patients (51\%) actually underwent EUS-FNA. Indeed, sensitivity, specificity, and diagnostic accuracy of $\mathrm{N}$ staging by EUS alone or EUS-FNA were similar except for a lower sensitivity of EUS-FNA ( $52 \%$ vs. $74 \%$ ). The negligible impact of EUS-FNA could be related to the close correlation of $\mathrm{T}$ and $\mathrm{N}$ stages in rectal cancer and the fact that most perirectal lymph nodes detected at EUS during rectal cancer staging are malignant.

In patients with perirectal lesions detected at EUS and a history of cancer (in the colorectum or elsewhere), EUS-FNA allowed detection of cancer relapse with a high diagnostic accuracy in a prospective and a retrospective series that included 84 patients in total $[36,118]$. In both studies, EUS-FNA was more accurate than EUS alone in diagnosing malignancy recurrence, at $92 \%$ vs. $69 \%$ in the largest study $(P<0.01)$ [118]. The latter study also found that EUS-FNA had a considerable impact on patient management in $26 \%$ of cases.

\section{Miscellaneous}

\subsection{Lymph nodes of unknown origin}

EUS-FNA allows accurate determination of the nature of lymph nodes of unknown origin (Evidence level $2+$ ). We recommend performing EUS-FNA of lymph nodes of unknown origin if these are accessible, no other significant lymph node is easily accessible (e.g., subcutaneous lymph node), and a pathological result would likely affect patient management (Recommendation grade $C$ ).

A prospective study has reported a $98 \%$ diagnostic accuracy of EUS-FNA (using a 19-G needle) in 104 patients who had lymph 
nodes of unknown origin located in the mediastinum or abdomen and which were accessible to EUS-FNA [87]. Subclassification of lymphoma was possible for 44 ( $92 \%$ ) of the 48 patients diagnosed with this condition. A retrospective study analyzed the results of EUS-FNA for enlarged periportal lymph nodes in 64 patients without identifiable malignancy or liver disease [119]. A malignancy (metastatic carcinoma or non-Hodgkin's lymphoma/ chronic lymphocytic leukemia) was diagnosed in $19 \%$ of patients. Specific techniques of EUS-FNA and of sample preservation are useful in this indication (see Technical Guideline for details) [1]. No data on the impact of EUS-FNA in this indication has been published so far.

\subsection{Adrenal gland masses}

EUS-FNA is an accurate and safe technique for sampling left adrenal gland masses (Evidence level 2+). In patients with lung cancer and an enlarged left adrenal gland, EUS-FNA of the left adrenal gland modifies disease stage and treatment strategy in approximately half of patients (Evidence level $2+$ ); it is recommended if a cytopathological result positive for malignancy is likely to change patient management (Recommendation grade C).

EUS-FNA of the left adrenal gland has been reported by a few centers and, more recently, EUS-FNA of the right adrenal gland has been reported by two centers [120-122]. No significant procedure-related complications have been reported to date. The diagnostic yield of EUS-FNA ranged between $76 \%$ and $100 \%$ in the largest series published, which included $24-85$ patients [121,123125]. Finally a study looked at the impact of EUS-FNA of left adrenal gland masses in unselected patients with established or suspected lung cancer; it showed a modification in TNM staging by EUS-FNA results in $70 \%$ of cases whereas treatment changed in $48 \%[126]$.

\subsection{Focal solid liver lesions}

Solid liver lesions may be safely sampled by EUS-FNA; the diagnostic yield and the impact on patient management are high (Evidence level $2+$ ). We recommend performing EUS-FNA of focal liver lesions accessible to EUS-FNA if: (i) a pathological result positive for malignancy would likely affect patient management, and (ii) the lesion is poorly accessible to percutaneous FNA or it is detected de novo by EUS or it has been sampled by percutaneous FNA with a nondiagnostic result (Recommendation grade $\mathrm{C}$ ).

EUS imaging of the liver is currently limited to the left lobe, the proximal part of the right lobe, the hilum, and part of the intrahepatic biliary tract, with variations related to the type of echoendoscope used and patient anatomy $[127,128]$.

A prospective study in 41 patients who had solid liver lesions visible at EUS showed that a specimen adequate for pathological examination could be obtained in most cases (98\%) with an acceptable morbidity rate (5\%; all complications were minor) [129]. Sensitivity and NPV for the diagnosis of malignancy were $94 \%$ and $78 \%$, respectively. Of note, these results were obtained by combining cytopathological and histopathological examination of microcores.

Two retrospective series included a total of 244 EUS-FNA procedures for solid liver lesions visible at EUS; the diagnostic yield was in the range of $80 \%-90 \%$, including cases where ultrasoundor CT-guided FNA had failed to yield a diagnosis $[68,130]$. In one study, one death was reported (mortality rate $0.6 \%$ ), due to cholangitis in a patient who was suspected to have an occluded biliary stent at the time of EUS. In both retrospective studies, EUS-FNA had an impact on clinical management in approximate- ly $90 \%$ of the patients who had a EUS-FNA sample positive for malignancy. No prospective study has compared percutaneous with EUS-guided FNA.

\subsection{False-positive cytopathological results}

The incidence of false-positive cytopathological results with EUSFNA samples ranges between $1.6 \%$ and 5.3\%. (Evidence level 2+). Flushing the working channel of the echoendoscope before every needle pass may reduce this risk (Evidence level $2-$ ). The possibility of a false-positive diagnosis should be kept in mind when interpreting cytopathological results of EUS-FNA, particularly for EUS-FNA of lymph nodes in patients with luminal cancers (Recommendation grade $C$ ). We suggest flushing the working channel of the echoendoscope before every needle pass and collection of microcores to help prevent this outcome (Recommendation grade $D$ ).

In a retrospective review of 188 patients who underwent surgery after having had a cytopathological result positive for malignancy at EUS-FNA, a false-positive diagnosis was identified in two pancreatic and one lymph node sample (false-positive rate 1.6\%) [131]. Interpretation errors were identified in two of the three cases. Gleeson et al. reported an incidence of false-positive cytopathological results of $5.3 \%$ by matching 377 EUS-FNA and surgical samples [132]. Discordant results were blindly assessed by three cytopathologists: reasons for false-positive results included epithelial cell contamination and pathological misinterpretation. Recently, in an ex vivo experiment, smears were prepared after sham EUS-FNA performed with an echoendoscope that had just been used in 13 patients with esophageal cancer (without FNA); the sham EUS-FNA was done either after extensive flushing of the working channel $(n=5)$ or not $(n=8)$. Neoplastic cells were detected on smears prepared from 6 of the 8 samples (75\%) obtained by sham EUS-FNA without flushing the working channel and in none of the 5 samples obtained by sham EUS-FNA after flushing the working channel [133]. In a prospective study performed in 140 patients, malignant cells were found in the luminal fluid aspirated through the echoendoscope suction channel in $48 \%$ of patients with luminal tumors (not influenced by FNA) and in $10 \%$ of patients after EUS-FNA of pancreatic tumors [134].

\subsection{Needle tract seeding}

Needle tract seeding is extremely rare with EUS-FNA (Evidence level 3).

Only three cases of needle tract seeding have been reported to date following EUS-FNA, with metastases located in the gastric or esophageal wall [135-137]. As discussed above, the risk of peritoneal seeding from pancreatic cancer could be lower after EUS-guided compared with percutaneous FNA [67].

\section{Use of this guideline \\ $\nabla$}

ESGE Guidelines represent a consensus of best practice based on the available evidence at the time of preparation. They may not apply in all situations and should be interpreted in the light of specific clinical situations and resource availability. Further controlled clinical studies may be needed to clarify aspects of these statements, and revision may be necessary as new data appear. Clinical consideration may justify a course of action at variance with these recommendations. ESGE Guidelines are intended to be an educational device for providing information that may assist endoscopists in providing care to patients. They are not rules and should not be construed as establishing a legal standard 
of care or as encouraging, advocating, requiring, or discouraging any particular treatment.

Competing interests: Alberto Larghi and Marc Giovannini have received research support from Cook Endoscopy Inc., Limerick, Ireland. Peter Vilmann has received a consultancy fee for EUSFNA needle development from Medi-Globe GmbH, Grassau, Germany.

\section{Institutions}

1 Service of Gastroenterology and Hepatology, Geneva University Hospitals, Geneva, Switzerland

2 Department of Gastroenterology and Hepatology, Medical Centre for Postgraduate Education and Department of Gastroenterology, The M. Sklodowska-Curie Memorial Cancer Centre and Institute of Oncology, Warsaw, Poland

${ }^{3}$ Digestive Endoscopy Unit, Catholic University, Rome, Italy

${ }^{4}$ Department of Surgical Gastroenterology, Herlev Hospital and Gentofte Hospital, Copenhagen University, Denmark

${ }^{5}$ Endoscopic Unit, Paoli-Calmettes Institut, Marseilles, France

${ }^{6}$ Endoscopic Unit, Cannes Hospital, Cannes, France

${ }^{7}$ Department of Gastroenterology, Hôpital Privé Jean Mermoz, Lyon, France

${ }^{8}$ Endoscopy Unit, Department of Gastroenterology, ICMDM, IDIBAPS, CIBER ehd, Hospital Clínic, Barcelona, Spain

${ }^{9}$ Division of Gastroenterology, Hospital Ramon, University of Alcala, Cajal, Madrid, Spain

\section{Acknowledgment}

The authors thank Dr. Geneviève Ranchin-Monges for helpful comments.

\section{References}

1 Polkowski M, Larghi A, Weynand B et al. Learning, techniques and complications of EUS-guided sampling. ESGE Technical Guideline. Endoscopy 2011 [In press]

2 Dumonceau JM, Riphaus A, Aparicio JR et al. European Society of Gastrointestinal Endoscopy, European Society of Gastroenterology and Endoscopy Nurses and Associates, and the European Society of Anaesthesiology Guideline: Non-anesthesiologist administration of propofol for GI endoscopy. Endoscopy 2010; 42: 960-974

3 Dumonceau J-M, Andriulli A, Deviere J et al. European Society of Gastrointestinal Endoscopy (ESGE) Guideline: prophylaxis of post-ERCP pancreatitis. Endoscopy 2010; 42: 503-515

4 Harbour R, Miller J. A new system for grading recommendations in evidence based guidelines. BMJ 2001; 323: 334-336

5 Polkowski M. Endoscopic ultrasound and endoscopic ultrasoundguided fine-needle biopsy for the diagnosis of malignant submucosal tumors. Endoscopy 2005; 37: 635-645

6 Polkowski M, Butruk E. Submucosal lesions. Gastrointest Endosc Clin N Am 2005; 15: $33-54$, viii.

7 Cantor MJ, Davila RE, Faigel DO. Yield of tissue sampling for subepithelial lesions evaluated by EUS: a comparison between forceps biopsies and endoscopic submucosal resection. Gastrointest Endosc 2006; 64: $29-34$

8 Hoda KM, Rodriguez SA, Faigel DO. EUS-guided sampling of suspected GI stromal tumors. Gastrointest Endosc 2009; 69: 1218-1223

9 Hunt GC, Smith PP, Faigel DO. Yield of tissue sampling for submucosal lesions evaluated by EUS. Gastrointest Endosc 2003; 57: 68 - 72

$10 \mathrm{Ji}$ J-S, Lee B-I, Choi K-Y et al. Diagnostic yield of tissue sampling using a bite-on-bite technique for incidental subepithelial lesions. Korean J Intern Med 2009; 24: 101 - 105

11 Sun S, Ge N, Wang C et al. Endoscopic band ligation of small gastric stromal tumors and follow-up by endoscopic ultrasonography. Surg Endosc 2007; 21: $574-578$

12 Zhou X-D, Lv N-H, Chen H-X et al. Endoscopic management of gastrointestinal smooth muscle tumor. World J Gastroenterol 2007; 13 : 4897-4902

13 Grubel P. Keyhole biopsy: an easy and better alternative to fine-needle aspiration or Tru-cut biopsy of submucosal gastrointestinal tumors. Endoscopy 2010; 42: 685

14 Lee CK, Chung I-K, Lee S-H et al. Endoscopic partial resection with the unroofing technique for reliable tissue diagnosis of upper GI subepi- thelial tumors originating from the muscularis propria on EUS (with video). Gastrointest Endosc 2010; 71: 188-194

15 Kojima T, Takahashi H, Parra-Blanco A et al. Diagnosis of submucosal tumor of the upper GI tract by endoscopic resection. Gastrointest Endosc 1999; 50: 516-522

16 Mekky MA, Yamao K, Sawaki A et al. Diagnostic utility of EUS-guided FNA in patients with gastric submucosal tumors. Gastrointest Endosc 2010; 71: 913-919

17 Philipper M, Hollerbach S, Gabbert HE et al. Prospective comparison of endoscopic ultrasound-guided fine-needle aspiration and surgical histology in upper gastrointestinal submucosal tumors. Endoscopy 2010; 42: 300-305

18 Akahoshi K, Sumida Y, Matsui N et al. Preoperative diagnosis of gastrointestinal stromal tumor by endoscopic ultrasound-guided fine needle aspiration. World J Gastroenterol 2007; 13: 2077-2082

19 Fernández-Esparrach G, Sendino O, Solé $M$ et al. Endoscopic ultrasound-guided fine-needle aspiration and trucut biopsy in the diagnosis of gastric stromal tumors: a randomized crossover study. Endoscopy 2010; 42: 292-299

20 Sepe PS, Moparty B, Pitman MB et al. EUS-guided FNA for the diagnosis of GI stromal cell tumors: sensitivity and cytologic yield. Gastrointest Endosc 2009; 70: 254-261

21 Yoshida S, Yamashita K, Yokozawa M et al. Diagnostic findings of ultrasound-guided fine-needle aspiration cytology for gastrointestinal stromal tumors: proposal of a combined cytology with newly defined features and histology diagnosis. Pathol Int 2009; 59: 712-719

22 Turhan N, Aydog G, Ozin Y et al. Endoscopic ultrasonography-guided fine-needle aspiration for diagnosing upper gastrointestinal submucosal lesions: A prospective study of 50 cases. Diagn Cytopathol 2010 Sept 10 [Epub ahead of print]

23 Polkowski M, Gerke W, Jarosz D et al. Diagnostic yield and safety of endoscopic ultrasound-guided trucut biopsy in patients with gastric submucosal tumors: a prospective study. Endoscopy 2009; 41: 329 334

24 Li SQ O'Leary TJ, Buchner SB et al. Fine needle aspiration of gastrointestinal stromal tumors. Acta Cytol 2001; 45: 9-17

25 Meara RS, Cangiarella J, Simsir A et al. Prediction of aggressiveness of gastrointestinal stromal tumours based on immunostaining with bcl2, Ki-67 and p53. Cytopathology 2007; 18: $283-289$

26 Wong NACS, Young R, Malcomson RDG et al. Prognostic indicators for gastrointestinal stromal tumours: a clinicopathological and immunohistochemical study of 108 resected cases of the stomach. Histopathology 2003; 43: 118-126

27 Al-Haddad M, Dewitt J. EUS-guided sampling of suspected GI mesenchymal tumors: cells, cores, or a combination?. Gastrointest Endosc 2009; 69: 1224-1227

28 Sepe PS, Brugge WR. A guide for the diagnosis and management of gastrointestinal stromal cell tumors. Nat Rev Gastroenterol Hepatol 2009; 6: 363-371

29 Boyce GA, Sivak MV, Rösch T et al. Evaluation of submucosal upper gastrointestinal tract lesions by endoscopic ultrasound. Gastrointest Endosc 1991: 37: 449-454

30 Agaimy A, Wünsch PH, Hofstaedter $F$ et al. Minute gastric sclerosing stromal tumors (GIST tumorlets) are common in adults and frequently show c-KIT mutations. Am J Surg Pathol 2007; 31: 113-120

31 Kawanowa K, Sakuma Y, Sakurai S et al. High incidence of microscopic gastrointestinal stromal tumors in the stomach. Hum Pathol 2006; 37: $1527-1535$

32 Nilsson B, Bümming P, Meis-Kindblom JM et al. Gastrointestinal stromal tumors: the incidence, prevalence, clinical course, and prognostication in the preimatinib mesylate era - a population-based study in western Sweden. Cancer 2005; 103: 821 - 829

33 Casali PG, Blay J-Y. ESMO/CONTICANET/EUROBONET panel of experts. Gastrointestinal stromal tumours: ESMO Clinical Practice Guidelines for diagnosis, treatment and follow-up. Ann Oncol 2010; 21 Suppl 5: v98-102

34 Demetri GD, Benjamin RS, Blanke CD et al. NCCN Task Force report: management of patients with gastrointestinal stromal tumor (GIST) - update of the NCCN clinical practice guidelines. J Natl Compr Canc Netw 2007; 5 Suppl 2: S1-29; quiz 30.

35 Novitsky YW, Kercher KW, Sing RF et al. Long-term outcomes of laparoscopic resection of gastric gastrointestinal stromal tumors. Ann Surg 2006; 243: 738 - 745: discussion 745-737.

36 Sasaki $Y$, Niwa $Y$, Hirooka $Y$ et al. The use of endoscopic ultrasoundguided fine-needle aspiration for investigation of submucosal and ex- 
trinsic masses of the colon and rectum. Endoscopy 2005; 37: 154160

37 Reeder MM, Olmsted WW, Cooper PH. Large gastric folds, local or widespread. JAMA 1974; 230: 273-274

38 Chambers LA, Clark WE. The endoscopic diagnosis of gastroesophageal malignancy. A cytologic review. Acta Cytol 1986; 30: 110-114

39 Ginès A, Pellise M, Fernández-Esparrach $G$ et al. Endoscopic ultrasonography in patients with large gastric folds at endoscopy and biopsies negative for malignancy: predictors of malignant disease and clinical impact. Am J Gastroenterol 2006; 101: 64-69

40 Pellisé Urquiza M, Fernández-Esparrach G, Solé M et al. Endoscopic ultrasound-guided fine needle aspiration: predictive factors of accurate diagnosis and cost-minimization analysis of on-site pathologist. Gastroenterol Hepatol 2007; 30: 319-324

41 Wiersema MJ, Vilmann P, Giovannini M et al. Endosonography-guided fine-needle aspiration biopsy: diagnostic accuracy and complication assessment. Gastroenterology 1997; 112: 1087-1095

42 Thomas T, Kaye PV, Ragunath $K$ et al. Endoscopic-ultrasound-guided mural trucut biopsy in the investigation of unexplained thickening of esophagogastric wall. Endoscopy 2009; 41: 335 - 339

43 Hartwig W, Schneider L, Diener MK et al. Preoperative tissue diagnosis for tumours of the pancreas. Br J Surg 2009; 96: 5-20

44 Mortenson MM, Katz MHG, Tamm EP et al. Current diagnosis and management of unusual pancreatic tumors. Am J Surg 2008; 196: $100-113$

45 Giovannini M. Contrast-enhanced endoscopic ultrasound and elastosonoendoscopy. Best Pract Res Clin Gastroenterol 2009; 23: 767 - 779

46 Iglesias-Garcia J, Larino-Noia J, Abdulkader I et al. Quantitative endoscopic ultrasound elastography: an accurate method for the differentiation of solid pancreatic masses. Gastroenterology 2010; 139 : $1172-1180$

47 Napoleon B, Alvarez-Sanchez MV, Gincoul $R$ et al. Contrast-enhanced harmonic endoscopic ultrasound in solid lesions of the pancreas: results of a pilot study. Endoscopy 2010; 42: 564-570

48 Khalid A, Nodit L, Zahid M et al. Endoscopic ultrasound fine needle aspirate DNA analysis to differentiate malignant and benign pancreatic masses. Am J Gastroenterol 2006; 101: 2493 - 2500

49 Bournet B, Souque A, Senesse P et al. Endoscopic ultrasound-guided fine-needle aspiration biopsy coupled with KRAS mutation assay to distinguish pancreatic cancer from pseudotumoral chronic pancreatitis. Endoscopy 2009; 41: 552 - 557

50 Maluf-Filho F, Kumar A, Gerhardt R et al. Kras mutation analysis of fine needle aspirate under EUS guidance facilitates risk stratification of patients with pancreatic mass. J Clin Gastroenterol 2007; 41: 906 910

51 Pellisé $M$, Castells A, Ginès A et al. Clinical usefulness of KRAS mutational analysis in the diagnosis of pancreatic adenocarcinoma by means of endosonography-guided fine-needle aspiration biopsy. Aliment Pharmacol Ther 2003; 17: 1299-1307

52 Eloubeidi MA, Varadarajulu S, Desai S et al. Value of repeat endoscopic ultrasound-guided fine needle aspiration for suspected pancreatic cancer. J Gastroenterol Hepatol 2008; 23: 567 - 570

53 Tadic M, Kujundzic M, Stoos-Veic T et al. Role of repeated endoscopic ultrasound-guided fine needle aspiration in small solid pancreatic masses with previous indeterminate and negative cytological findings. Dig Dis 2008; 26: 377 - 382

54 Figueiredo FAF, Giovannini M, Monges $G$ et al. Pancreatic endocrine tumors: a large single-center experience. Pancreas 2009; 38: 936-940

55 Pais SA, Al-Haddad M, Mohamadnejad M et al. EUS for pancreatic neuroendocrine tumors: a single-center, 11-year experience. Gastrointest Endosc 2010; 71: 1185-1193

56 Figueiredo FAF, Giovannini M, Monges G et al. EUS-FNA predicts 5-year survival in pancreatic endocrine tumors. Gastrointest Endosc 2009; 70: $907-914$

57 Fasanella KE, McGrath KM, Sanders $M$ et al. Pancreatic endocrine tumor EUS-guided FNA DNA microsatellite loss and mortality. Gastrointest Endosc 2009; 69: 1074-1080

58 Piani C, Franchi GM, Cappelletti C et al. Cytological Ki-67 in pancreatic endocrine tumours: an opportunity for pre-operative grading. Endocr Relat Cancer 2008; 15: 175-181

59 Chatzipantelis $P$, Konstantinou P, Kaklamanos $M$ et al. The role of cytomorphology and proliferative activity in predicting biologic behavior of pancreatic neuroendocrine tumors: a study by endoscopic ultrasound-guided fine-needle aspiration cytology. Cancer 2009; 117: $211-216$
60 Fritscher-Ravens A, Sriram PV, Krause C et al. Detection of pancreatic metastases by EUS-guided fine-needle aspiration. Gastrointest Endosc 2001; 53: $65-70$

61 Mizuno N, Bhatia V, Hosoda $W$ et al. Histological diagnosis of autoimmune pancreatitis using EUS-guided trucut biopsy: a comparison study with EUS-FNA. J Gastroenterol 2009; 44: 742 - 750

62 Erturk SM, Mortelé KJ, Tuncali K et al. Fine-needle aspiration biopsy of solid pancreatic masses: comparison of CT and endoscopic sonography guidance. AJR Am J Roentgenol 2006; 187: 1531 - 1535

63 Horwhat JD, Paulson EK, McGrath Ket al. A randomized comparison of EUS-guided FNA versus CT or US-guided FNA for the evaluation of pancreatic mass lesions. Gastrointest Endosc 2006; 63: 966-975

64 Mallery JS, Centeno BA, Hahn PF et al. Pancreatic tissue sampling guided by EUS, CT/US, and surgery: a comparison of sensitivity and specificity. Gastrointest Endosc 2002; 56: 218 - 224

65 Volmar KE, Vollmer RT, Jowell PS et al. Pancreatic FNA in 1000 cases: a comparison of imaging modalities. Gastrointest Endosc 2005; 61: 854-861

66 Chen VK, Arguedas MR, Kilgore ML et al. A cost-minimization analysis of alternative strategies in diagnosing pancreatic cancer. Am J Gastroenterol 2004; 99: 2223-2234

67 Micames C, Jowell PS, White R et al. Lower frequency of peritoneal carcinomatosis in patients with pancreatic cancer diagnosed by EUSguided FNA vs. percutaneous FNA. Gastrointest Endosc 2003; 58 : $690-695$

68 Dewitt J, Leblanc J, McHenry L et al. Endoscopic ultrasound-guided fine needle aspiration cytology of solid liver lesions: a large singlecenter experience. Am J Gastroenterol 2003; 98: 1976-1981

69 DeWitt J, LeBlanc J, McHenry L et al. Endoscopic ultrasound-guided fine-needle aspiration of ascites. Clin Gastroenterol Hepatol 2007; 5: 609-615

70 DeWitt J, Yu M, Al-Haddad MA et al. Survival in patients with pancreatic cancer after the diagnosis of malignant ascites or liver metastases by EUS-FNA. Gastrointest Endosc 2010; 71: 260-265

71 Mortensen MB, Pless T, Durup J et al. Clinical impact of endoscopic ultrasound-guided fine needle aspiration biopsy in patients with upper gastrointestinal tract malignancies. A prospective study. Endoscopy 2001; 33: $478-483$

72 Chaya C, Nealon WH, Bhutani MS. EUS or percutaneous CT/US-guided FNA for suspected pancreatic cancer: when tissue is the issue. Gastrointest Endosc 2006; 63: 976-978

73 Brugge WR, Lewandrowski K, Lee-Lewandrowski E et al. Diagnosis of pancreatic cystic neoplasms: a report of the cooperative pancreatic cyst study. Gastroenterology 2004; 126: 1330-1336

74 van der Waaij LA, van Dullemen HM, Porte RJ. Cyst fluid analysis in the differential diagnosis of pancreatic cystic lesions: a pooled analysis. Gastrointest Endosc 2005; 62: 383 - 389

75 Khalid A, Zahid M, Finkelstein SD et al. Pancreatic cyst fluid DNA analysis in evaluating pancreatic cysts: a report of the PANDA study. Gastrointest Endosc 2009; 69: 1095-1102

76 Sawhney MS, Devarajan S, O'Farrel P et al. Comparison of carcinoembryonic antigen and molecular analysis in pancreatic cyst fluid. Gastrointest Endosc 2009; 69: 1106-1110

77 Cuoghi A, Farina A, Z'graggen K et al. Role of proteomics to differentiate between benign and potentially malignant pancreatic cysts. J Proteome Res 2011; 10: 2664-2670. Epub 2011 Apr 6.

78 Al-Haddad M, Gill KR, Raimondo $M$ et al. Safety and efficacy of cytology brushings versus standard fine-needle aspiration in evaluating cystic pancreatic lesions: a controlled study. Endoscopy 2010; 42: $127-132$

79 Sendino O, Fernández-Esparrach G, Solé M et al. Endoscopic ultrasonography-guided brushing increases cellular diagnosis of pancreatic cysts: A prospective study. Dig Liver Dis 2010; 42: 877-881

80 Thomas T, Bebb J, Mannath J et al. EUS-guided pancreatic cyst brushing: a comparative study in a tertiary referral centre. JOP 2010; 11 : $163-169$

81 Bruno $M$, Bosco $M$, Carucci P et al. Preliminary experience with a new cytology brush in EUS-guided FNA. Gastrointest Endosc 2009; 70: $1220-1224$

82 Catalano MF, Sivak MV, Rice T et al. Endosonographic features predictive of lymph node metastasis. Gastrointest Endosc 1994; 40: 442 446

83 Puli S-R, Batapati Krishna Reddy J, Bechtold M-L et al. Endoscopic ultrasound: its accuracy in evaluating mediastinal lymphadenopathy? 
A meta-analysis and systematic review. World J Gastroenterol 2008; 14: $3028-3037$

84 Avritscher R, Krishnamurthy S, Ensor J et al. Accuracy and sensitivity of computed tomography-guided percutaneous needle biopsy of pulmonary hilar lymph nodes. Cancer 2010; 116: 1974-1980

85 Sobel JM, Lai R, Mallery S et al. The utility of EUS-guided FNA in the diagnosis of metastatic breast cancer to the esophagus and the mediastinum. Gastrointest Endosc 2005; 61: 416-420

86 Agarwal B, Gogia S, Eloubeidi MA et al. Malignant mediastinal lymphadenopathy detected by staging EUS in patients with pancreaticobiliary cancer. Gastrointest Endosc 2005; 61: 849-853

87 Yasuda I, Tsurumi H, Omar S et al. Endoscopic ultrasound-guided fineneedle aspiration biopsy for lymphadenopathy of unknown origin. Endoscopy 2006; 38: 919-924

88 Ribeiro A, Pereira D, Escalón MP et al. EUS-guided biopsy for the diagnosis and classification of lymphoma. Gastrointest Endosc 2010; 71: $851-855$

89 Berzosa M, Tsukayama DT, Davies SF et al. Endoscopic ultrasoundguided fine-needle aspiration for the diagnosis of extra-pulmonary tuberculosis. Int J Tuberc Lung Dis 2010; 14: 578-584

90 Michael H, Ho S, Pollack B et al. Diagnosis of intra-abdominal and mediastinal sarcoidosis with EUS-guided FNA. Gastrointest Endosc 2008; 67: $28-34$

91 Iwashita T, Yasuda I, Doi S et al. The yield of endoscopic ultrasoundguided fine needle aspiration for histological diagnosis in patients suspected of stage I sarcoidosis. Endoscopy 2008; 40: 400-405

92 Puri R, Vilmann P, Sud R et al. Endoscopic ultrasound-guided fine-needle aspiration cytology in the evaluation of suspected tuberculosis in patients with isolated mediastinal lymphadenopathy. Endoscopy 2010; 42: $462-467$

93 Diehl DL, Cheruvattath R, Facktor MA et al. Infection after endoscopic ultrasound-guided aspiration of mediastinal cysts. Interact Cardiovasc Thorac Surg 2010; 10: 338 - 340

94 Mahady SE, Moss A, Kwan V. EUS-guided drainage of a mediastinal collection complicating FNA of a bronchogenic cyst. Gastrointest Endosc 2011; 73: 1306-1308. Epub 2010 Dec 15

95 Ryan AG, Zamvar V, Roberts SA. Iatrogenic candidal infection of a mediastinal foregut cyst following endoscopic ultrasound-guided fine-needle aspiration. Endoscopy 2002; 34: 838 - 839

96 Wildi SM, Hoda RS, Fickling $W$ et al. Diagnosis of benign cysts of the mediastinum: the role and risks of EUS and FNA. Gastrointest Endosc 2003; 58: $362-368$

97 Annema JT, Veseliç M, Versteegh MI et al. Mediastinitis caused by EUSFNA of a bronchogenic cyst. Endoscopy 2003; 35: 791 - 793

98 Savides TJ, Perricone A. Impact of EUS-guided FNA of enlarged mediastinal lymph nodes on subsequent thoracic surgery rates. Gastrointest Endosc 2004; 60: 340 - 346

99 Catalano MF, Rosenblatt ML, Chak A et al. Endoscopic ultrasoundguided fine needle aspiration in the diagnosis of mediastinal masses of unknown origin. Am J Gastroenterol 2002; 97: 2559-2565

100 Hirdes MMC, Schwartz MP, Tytgat KMAJ et al. Performance of EUS-FNA for mediastinal lymphadenopathy: impact on patient management and costs in low-volume EUS centers. Surg Endosc 2010; 24: 2260 2267

101 Larsen SS, Krasnik M, Vilmann P et al. Endoscopic ultrasound guided biopsy of mediastinal lesions has a major impact on patient management. Thorax 2002; 57: 98 - 103

102 Catalano MF, Nayar R, Gress F et al. EUS-guided fine needle aspiration in mediastinal lymphadenopathy of unknown etiology. Gastrointest Endosc 2002; 55: 863-869

103 Polkowski $M$. Endosonographic staging of upper intestinal malignancy. Best Pract Res Clin Gastroenterol 2009; 23: 649-661

104 Hassan H, Vilmann P, Sharma V. Impact of EUS-guided FNA on management of gastric carcinoma. Gastrointest Endosc 2010; 71: 500 504

105 Stahl M, Budach W, Meyer H-J et al. Esophageal cancer: Clinical Practice Guidelines for diagnosis, treatment and follow-up. Ann Oncol 2010; 21 Suppl 5: v46-49

106 Eloubeidi MA, Wallace MB, Reed CE et al. The utility of EUS and EUSguided fine needle aspiration in detecting celiac lymph node metastasis in patients with esophageal cancer: a single-center experience. Gastrointest Endosc 2001; 54: 714-719

107 Giovannini M, Monges G, Seitz JF et al. Distant lymph node metastases in esophageal cancer: impact of endoscopic ultrasound-guided biopsy. Endoscopy 1999; 31: 536-540
108 Parmar KS, Zwischenberger JB, Reeves AL et al. Clinical impact of endoscopic ultrasound-guided fine needle aspiration of celiac axis lymph nodes (M1a disease) in esophageal cancer. Ann Thorac Surg 2002; 73: 916-920; discussion 920-921.

109 Vazquez-Sequeiros E, Norton ID, Clain JE et al. Impact of EUS-guided fine-needle aspiration on lymph node staging in patients with esophageal carcinoma. Gastrointest Endosc 2001; 53: 751 - 757

110 Vazquez-Sequeiros E, Wiersema MJ, Clain JE et al. Impact of lymph node staging on therapy of esophageal carcinoma. Gastroenterology 2003; 125: $1626-1635$

111 Stahl M, Budach W, Meyer H-J et al. Esophageal cancer: Clinical Practice Guidelines for diagnosis, treatment and follow-up. Ann Oncol 2010; 21 Suppl 5: v46-49

112 McGrath K, Brody D, Luketich J et al. Detection of unsuspected left hepatic lobe metastases during EUS staging of cancer of the esophagus and cardia. Am J Gastroenterol 2006; 101: 1742 - 1746

113 Marsman WA, Brink MA, Bergman JJ et al. Potential impact of EUSFNA staging of proximal lymph nodes in patients with distal esophageal carcinoma. Endoscopy 2006; 38: 825-829

114 Keswani RN, Early DS, Edmundowicz SA et al. Routine positron emission tomography does not alter nodal staging in patients undergoing EUS-guided FNA for esophageal cancer. Gastrointest Endosc 2009; 69: $1210-1217$

115 McDonough PB, Jones DR, Shen KR et al. Does FDG-PET add information to EUS and CT in the initial management of esophageal cancer? A prospective single center study. Am J Gastroenterol 2008; 103: $570-574$

116 Cerfolio RJ, Bryant AS, Ohja B et al. The accuracy of endoscopic ultrasonography with fine-needle aspiration, integrated positron emission tomography with computed tomography, and computed tomography in restaging patients with esophageal cancer after neoadjuvant chemoradiotherapy. J Thorac Cardiovasc Surg 2005; 129: 1232 - 1241

117 Harewood GC, Wiersema MJ, Nelson $H$ et al. A prospective, blinded assessment of the impact of preoperative staging on the management of rectal cancer. Gastroenterology 2002; 123: 24-32

118 Hünerbein $M$, Totkas S, Moesta KT et al. The role of transrectal ultrasound-guided biopsy in the postoperative follow-up of patients with rectal cancer. Surgery 2001; 129: 164-169

119 Krishna NB, Gardner L, Collins BT et al. Periportal lymphadenopathy in patients without identifiable pancreatobiliary or hepatic malignancy. Clin Gastroenterol Hepatol 2006; 4: 1373-1377

120 Eloubeidi MA, Morgan DE, Cerfolio RJ et al. Transduodenal EUS-guided FNA of the right adrenal gland. Gastrointest Endosc 2008; 67: 522 527

121 Eloubeidi MA, Black KR, Tamhane A et al. A large single-center experience of EUS-guided FNA of the left and right adrenal glands: diagnostic utility and impact on patient management. Gastrointest Endosc 2011; 71: 745-753

122 DeWitt JM. Endoscopic ultrasound-guided fine-needle aspiration of right adrenal masses: report of 2 cases. J Ultrasound Med 2008; 27: $261-267$

123 DeWitt J, Alsatie M, LeBlanc J et al. Endoscopic ultrasound-guided fine-needle aspiration of left adrenal gland masses. Endoscopy 2007; 39: $65-71$

124 Jhala NC, Jhala D, Eloubeidi MA et al. Endoscopic ultrasound-guided fine-needle aspiration biopsy of the adrenal glands. Cancer 2004; 102: $308-314$

125 Schuurbiers OCJ, Tournoy KG, Schoppers HJ et al. EUS-FNA for the detection of left adrenal metastasis in patients with lung cancer. Lung Cancer 2011 Jan 27 [Epub ahead of print]

126 Bodtger U, Vilmann P, Clementsen P et al. Clinical impact of endoscopic ultrasound-fine needle aspiration of left adrenal masses in established or suspected lung cancer. J Thorac Oncol 2009; 4: 1485-1489

127 Fritscher-Ravens A, Broering DC, Knoefel WT et al. EUS-guided fineneedle aspiration of suspected hilar cholangiocarcinoma in potentially operable patients with negative brush cytology. Am J Gastroenterol 2004; 99: 45-51

128 Frossard JL, Dumonceau J. The role of EUS in the biliary system. In: Shami VM, Kahaleh $M$ eds. Endoscopic ultrasound. New York: Humana Press; 2010: 371 - 390

129 Hollerbach S, Willert J, Topalidis T et al. Endoscopic ultrasound-guided fine-needle aspiration biopsy of liver lesions: histological and cytological assessment. Endoscopy 2003; 35: $743-749$ 
130 tenBerge J, Hoffman BJ, Hawes RH et al. EUS-guided fine needle aspiration of the liver: indications, yield, and safety based on an international survey of 167 cases. Gastrointest Endosc 2002; 55: 859-862

131 Schwartz DA, Unni KK, Levy MJ et al. The rate of false-positive results with EUS-guided fine-needle aspiration. Gastrointest Endosc 2002; 56: $868-872$

132 Gleeson FC, Kipp BR, Caudill JL et al. False positive endoscopic ultrasound fine needle aspiration cytology: incidence and risk factors. Gut 2010; 59: 586-593

133 van Hemel BM, Lamprou AA, Weersma $R$ et al. Procedure-related, false-positive cytology results during EUS-guided FNA in patients with esophageal cancer. Gastrointest Endosc 2010; 71: 1130-1133

134 Levy MJ, Gleeson FC, Campion MB et al. Prospective cytological assessment of gastrointestinal luminal fluid acquired during EUS: a potential source of false-positive FNA and needle tract seeding. Am J Gastroenterol 2010; 105: 1311-1318
135 Paquin SC, Gariépy G, Lepanto L et al. A first report of tumor seeding because of EUS-guided FNA of a pancreatic adenocarcinoma. Gastrointest Endosc 2005; 61: 610-611

136 Shah JN, Fraker D, Guerry D et al. Melanoma seeding of an EUS-guided fine needle track. Gastrointest Endosc 2004; 59: 923-924

137 Doi S, Yasuda I, Iwashita $T$ et al. Needle tract implantation on the esophageal wall after EUS-guided FNA of metastatic mediastinal lymphadenopathy. Gastrointest Endosc 2008; 67: 988-990

\section{Appendix e1-e2 are available online:}

online content viewable at:

www.thieme-connect.de/ejournals/abstract/endoscopy/ doi/10.1055/s-0030-1256754 